\begin{tabular}{|c|l|}
\hline Title & Reflection on success and failures: scale development and validation \\
\hline Author(s) & Matsuo, Makoto \\
\hline Citation & Journal of workplace learning, 32(8), 615-626 \\
\hline https://doi.org/10.1108/JWL-07-2020-0117 \\
\hline Issue Date & 2020-11-14 \\
\hline Doc URL & http://hdl.handle.net/2115/83839 \\
\hline Rights(URL) & https://reativecommons.org/icenses/by-nc/4.0/ \\
\hline Type & article (author version) \\
\hline File Information & Matsuo (JWL 2020) self-archiving.pdf \\
\hline
\end{tabular}

Instructions for use 
Journal of Workplace Learning, Vol. 32 No. 8, pp. 615-626, 2020.

DOI 10.1108/JWL-07-2020-0117

\title{
Reflection on Success and failures: Scale development and validation
}

\author{
Makoto Matsuo \\ Graduate School of Economics and Business Administration, Hokkaido University, \\ Sapporo, Japan
}

\begin{abstract}
Purpose - Although positive psychology emphasizes the importance of reflecting on success in promoting strengths use and self-efficacy, no research has developed a measure of reflection on success. The purpose of this study is to develop and validate the scales for reflection on success and failures.

Design/methodology/approach - Study 1 was conducted to extract the dimensions of reflection on success and failures using survey data from nurses $(\mathrm{n}=298)$, while Study 2 involved validation of the scales using a two-wave survey of physical therapists $(n=291)$.

Findings - In Study 1, the factors of "reflection on success" and "reflection on failures" were extracted by exploratory factor analysis. In Study 2, the discriminant validity of the two scales was established via confirmatory factor analyses. The structural equation modeling results indicated that reflection on success promoted work authenticity, work engagement, and strengths use, while reflection on failures only promoted work engagement, indicating the convergent validity of the scales.
\end{abstract}

Research limitations/implications - As the research subjects were medical professionals in 
Japan, the scales need to be validated with samples from a wide range of occupations and cultural backgrounds, in future research.

Originality/value - The present research expands the literature on reflection and strengthsbased approach by introducing the "success-failures" dimension based on positive psychology, broaden-and-build theory, and job demands-resources theory.

\section{Introduction}

Several studies rooted in positive psychology have observed that the "strengths-based learning strategy" that focuses on increasing one's strengths, has stronger effects on perceived competence and performance than the "deficit-based learning strategy" that emphasizes improving upon one's shortcomings and deficits (Hiemstra and Van Yperen, 2015; Van Woerkom et al., 2016a). It also has been found that the use of one's strengths is positively related to self-esteem (Wood et al., 2011), psychological well-being (Govindji and Linley, 2007), quality of life (Proctor et al., 2011), and life satisfaction (Allan and Duffy, 2014; Douglass and Duffy, 2015).

It is important to note here that individuals' strengths can be identified by reflecting on success. For example, a positive psychology training method called "Three good things," in which participants are asked to write down three good things that happened each day and to reflect on why they happened, has been proven to be able to enhance self-efficacy and happiness (Guo et al., 2019; Mongrain and Anselmo-Matthews, 2012; Seligman et al., 2005, 2009). Similarly, in strengths-based performance appraisal, supervisors ask subordinates to recount their success stories to identify their strengths, and to find new ways to utilize them (BouskilaYam and Kluger, 2011).

Despite its importance, prior studies on the strengths-based approach have failed to 
quantitatively examine the effect of reflection on success. Considering that reflection plays a key role in learning and innovation (Hatton and Smith, 1995; Kember et al., 2000; Kolb, 1984; Korthagen, 2005; West, 2000), it is necessary to develop a measurement scale of reflection on success. In addition, deficit correction behaviors have been shown not to improve employees' performance (Van Woerkom et al., 2016a), while mistakes or errors are believed to be an important source of learning (Edmondson, 2004; Reason, 1990). However, reflection on failures has also never been quantitatively investigated.

To address the research gap, this study developed and validated the scales of reflection on success and failures, drawing on positive psychology (Peterson and Seligman, 2004; Seligman et al., 2005, 2009), broaden-and-build theory (Fredrickson, 2001), and job demandsresources (JD-R) theory (Bakker and Demerouti, 2014, 2017). The main contribution of this study is to extend the literature on reflection and the strengths-based approach by developing reflection on success and reflection on failures scales, which have different effects on outcomes such as work authenticity and strengths use.

\section{Theoretical framework}

\section{Reflection and learning}

Reflection refers to "deliberate thinking about action with a view to its improvement" (Hatton and Smith, 1995, p. 40). According to experiential learning theories, individuals learn from their experiences through reflection (Kolb, 1984; Korthagen, 2005). For example, Kolb (1984) proposed a four-step experiential learning model, which consists of "concrete experience," "reflective observation," "abstract conceptualization," and "active experimentation." This

model indicates that individuals learn by reflecting on their experience, gaining abstract concepts or lessons through reflection, and applying them into new experiences. Similarly, 
Korthagen (2005) provided a model, including "action," "looking back on the action," "awareness of essential aspects," "creating alternative methods of action," and "trial." This indicates that individuals learn by reflecting on their actions, identifying essential aspects, and creating alternative ideas for action. These models suggest that reflection in action plays a critical role in professional development (Nilsen et al., 2012; Schön, 1983).

Previous studies have conceptualized reflection from the perspective of "general critical" and "positive - negative." Specifically, (general) reflection focuses on the immediate and current details of a task or problem, while critical reflection focuses on taken-for-granted assumptions to seek alternative ways of reasoning and behaving (Gray, 2007; Kember et al., 2000; Mezirow, 1990; Reynolds, 1998). Meanwhile, Fritz and Sonnentag (2006) have examined positive work reflection and negative work reflection during vacation. That is, individuals who engage in positive work reflection tend to recall the positive aspects of their job experience, while those who engage in negative work reflection tend to recall the negative aspects of their job experience.

It is important to note that "positive-negative" reflection proposed by Fritz and Sonnentag (2006) should be distinguished from "success-failures" reflection investigated in this article. The former just refers to the recall of positive and negative events, while the latter focuses on the review on success and failures for improvement. Drawing on Hatton and Smith (1995), the present research defined "reflection on success" as deliberate thinking about experiences of success to increase one's strengths; and "reflection on failures" as deliberate thinking about experiences of failures to improve one's weaknesses. Deliberate thinking involves abstract conceptualization (Kolb, 1984) and awareness of essential aspects (Korthagen, 2005) for next actions. 


\section{Strengths-based approach and related theories}

Based on positive psychology, the "strengths-based approach" has been proposed in performance appraisal research, whereby managers ask employees to recall their successes, identify their strengths, and apply them to improve performance (Bouskila-Yam and Kluger, 2011; Kluger and Nir, 2010). As mentioned earlier, Hiemstra and Van Yperen (2015) have identified two types of self-regulated learning strategies: The "strengths-based strategy" and "deficit-based strategy." Individuals adopting strengths-based strategy tend to identify and increase their strengths, while those adopting the deficit-based strategy tend to identify and improve their shortcomings. An experimental study has revealed that college students adopting the strengths-based strategy show higher intrinsic motivation, and perform better than those adopting the deficit-based strategy (Hiemstra and Van Yperen, 2015).

The strengths-based approach can be explained by Fredrickson's (2001) “broaden-andbuild theory" (Bowers, 2009). The theory postulates that positive emotions created by experience broaden thought-action repertoires, which stimulate individuals to build physical, intellectual, social, and psychological resources (Fredrickson, 2001). The strengths-based approach is also interpreted by the JD-R theory, assuming that personal resources, i.e. individuals' beliefs about their ability to control their environment (e.g., self-efficacy), promote work engagement (Bakker and Demerouti, 2014, 2017). Bakker and Demerouti (2014) stated that employees who use their strengths are likely to have stronger self-efficacy and be engaged in their work.

According to the "strengths-based approach" (Bouskila-Yam and Kluger, 2011; Hiemstra and Van Yperen, 2015; Kluger and Nir, 2010) and "Three good things" (Seligman et al., 2005, 2009), reflection on success may enhance authentic happiness and engagement at work by identifying and using strengths. Therefore, this study hypothesized that reflection on success may be positively related to strengths use, work authenticity, and work engagement. 
These hypotheses are based on the rationale that positive emotion caused by reflection on success enables employees to identify their strengths and broaden action repertoires, which stimulate their personal resources, as suggested by the broaden-and-build theory (Fredrickson, 2001) and JD-R theory (Bakker and Demerouti, 2014, 2017). This study also predicted that reflection on success enhances work authenticity, i.e. the extent to which individuals act in accordance with their values, beliefs, and characteristics (Harter, 2002; Metin et al., 2016), because employees are likely to be true to their traits when they succeed.

On the other hand, the present research predicted that reflection on failures might not have an influence on strengths use and work authenticity. This is because it is difficult to identify one's strengths and the positive true self from failed experience. As shown earlier, the strengths-based strategy is better than the deficit-based strategy in promoting intrinsic motivation and performance (Hiemstra and Van Yperen, 2015). Similarly, Van Woerkom et al. (2016a) also reported that deficit correction behavior was not related to performance. However, it should be noted that failures, mistakes, and errors are deemed important sources of learning and future performance (Edmondson, 2004; Reason, 1990). The models of experiential learning (Kolb, 1984) and reflection (Korthagen, 2005) suggest that both success and failures are necessary to improve one's capabilities. Thus, it was predicted that "reflection on failures" is positively related to work engagement.

\section{Scale development and validation procedure}

To develop the scale, this study followed the procedures proposed by Hinkin (1998), which consists of item generation, scale development, and scale evaluation (Andrews \& Kacmar, 2001). Hinkin's (1998) approach is a well-regarded (Judge and Douglas, 2009) and widely accepted scale development procedure (Choi and Moran, 2009), and it has been applied for developing scales in the fields of organizational behaviors and applied psychology (e.g., 
Chuang et al., 2016; Holt et al., 2007; Wilson and Baumann, 2015). Although Churchill (1979) provided a similar procedure for developing measures of marketing construct, it has been mainly applied in marketing and tourism research (e.g., Gilliam and Voss, 2013; Hung and Petrick, 2011). Therefore, Hinkin's (1998) procedure was adopted in the present research.

Specifically, this study conducted exploratory factor analysis (EFA) and confirmatory factor analyses (CFAs) with different samples. In Study 1, survey data from nurses were analyzed using EFA to extract the dimensions of reflection. In Study 2, two-wave survey data from physical therapists were analyzed to validate the scale using CFA and SEM. Medical professionals were selected as samples because they are required to critically reflect on their work processes in stressful environments (Hayes et al., 2010; Vendrely, 2005). Before the analyses, items for the scales were developed based on previous research on reflection.

The items of reflection on success and failures were collected from West (2000) and Kember et al. (2000) for two reasons. First, West (2000) provided a representative scale for individual reflection at work, which has been applied in team reflection studies (e.g., Schippers, Homan, and Van Knippenberg, 2013). Second, Kember et al. (2000) is one of the few quantitative studies on individual reflection in higher education. The present research adopted three items from West's (2000) scale and two items from Kember et al.'s (2000) scale (Table 1). The number of items were determined, following Hinkin's (1998) recommendation, to be between four and six. Although each item was identical between the two scales, some wordings were changed as follows: "I often reflect upon if I have been working effectively (reflection on success)", and "I often reflect upon why I have not been able to work effectively (reflection on failures)." Since the questionnaires in Studies 1 and 2 were in Japanese, back translation (Cascio, 2012) was performed to minimize the discrepancies between the original English versions and the translated questions. 


\section{Study 1: Explorative examination}

The purpose of Study 1 was to exploratively examine the construct validity and internal consistency of the scale using EFA and Cronbach's alphas. Acute hospital nurses were selected as the sample because they are frequently prone to making decisions in demanding work environments (Hayes et al., 2010), where reflection is imperative for task performance.

\section{Methods}

Procedure and participants Data were collected from nurses at an acute hospital in Japan. The questionnaires were delivered to 361 nurses through the administrative office of the nursing department, and 298 completed responses were returned after removing the missing values (the response rate was $82.5 \%$ ). The participants were $95.0 \%$ female and $88.6 \%$ non-managers. Their average tenure was 13.6 years $(\mathrm{SD}=9.6$ years). The age distributions were: $20-29(25.8 \%), 30$ 39 (20.1\%), 40-49 (33.6\%), and above 50 years $(20.4 \%)$.

Measures Reflection on success and failures were assessed with a five-item scale, respectively (Table 1), based on a five-point Likert scale ranging from 1 (strongly disagree) to 5 (strongly agree).

\section{Results}

The Cronbach's alphas were .93 for reflection on success and .87 for reflection on failures, which were above the recommended value of .70, demonstrating sufficient internal consistency.

To examine whether the two factors can be distinguished from each other, EFA (principal factor method with oblique rotation) was performed. The factors were retained when the Eigenvalue was greater than 1 (Kaiser criterion). As hypothesized, two factors were extracted (explained $64.4 \%$ of the variance), and all factor loadings on related factors were 
above .40 (Hinkin, 1998). These results provide support for the hypothesized dimensions of reflection on success and failures. To establish the validity of the scales, the dimensional structure must be replicated using other samples (Hinkin, 1998).

\section{Table 1.}

Reflection on success and failures items

\begin{tabular}{|c|c|c|c|}
\hline \multirow[b]{2}{*}{ Reflection on success ( $\alpha=.93$ for Study $1 ; \alpha=.87$ for Study 2 ) } & \multicolumn{2}{|c|}{$\begin{array}{c}\text { EFA } \\
\text { Study } 1 \\
(\mathrm{n}=298)\end{array}$} & \multirow[t]{2}{*}{$\begin{array}{c}\text { CFA } \\
\text { Study } 2 \\
(\mathrm{n}=291)\end{array}$} \\
\hline & $F 1$ & $F 2$ & \\
\hline I often review my work successes and re-evaluate them for a better future & .77 & .08 & .70 \\
\hline I often reflect upon if I have been working effectively & .87 & -.02 & .72 \\
\hline I often review the prevailing approaches for getting my job done & .83 & .05 & .73 \\
\hline I often reflect on my work behaviors to see if I could have done something better & .83 & .01 & .79 \\
\hline I often re-appraise my successful work experience so I can learn from it and improve for my next performance & .91 & -.07 & .83 \\
\hline \multicolumn{4}{|l|}{ Reflection on failures $(\alpha=.87$ for Study $1 ; \alpha=.81$ for Study 2 ) } \\
\hline I often review my work failures and re-evaluate them for a better future & -.03 & .68 & .59 \\
\hline I often reflect upon why I have not been able to work effectively & -.05 & .74 & .62 \\
\hline I often review any ineffective methods I have used for getting the job done & .12 & .74 & .68 \\
\hline I often reflect on my ineffective work actions to see whether I could have improved on what I did. & .01 & .79 & .76 \\
\hline I often re-appraise my work failures so I can learn from it and improve for my next performance & .02 & .78 & .75 \\
\hline
\end{tabular}

Notes . Figures in EFA are standardized factor loadings of principal factor analysis with oblique rotation. Figures in CFA are standardized estimates of two-factor solution $\left(\chi^{2}=76.76, d f=34, \mathrm{CFI}=.942\right.$, SRMR $=.045$, RMSEA $\left.=.066\right)$.

\section{Study 2: Discriminant and convergent validity}

The purpose of Study 2 was to establish the discriminant and convergent validity of reflection on success and failures using a two-wave survey data of physical therapists. They were selected because critical thinking skills are required to perform their tasks (Vendrely, 2005). First, a series of CFAs were conducted to assess the discriminant validity of the scales. Then, the convergent validity was examined by examining the effects of reflection on successes and failures on work authenticity, work engagement, and strengths use, using SEM. These criteria were chosen based on positive psychology assuming that reflecting on success enables individuals to identify their strengths and true-self, and work happily (Peterson and Seligman, 2004; Seligman et al., 2005). 
It was predicted that reflection on success would be positively related to work authenticity, work engagement, and strengths use. It was also predicted that reflection on failures would have no significant effect on work authenticity and strengths use, since it is difficult to identify one's strengths from failures. However, individuals who reflect on their failures are likely to be engaged in their work because they try to improve their capacities.

\section{Methods}

Procedure and participants. A two-wave survey with a one-month interval was conducted with physical therapists at 40 Japanese healthcare institutions. The questionnaires were delivered to 382 physical therapists through an administrative physical therapist association office of a Japanese prefecture, and 291 were returned after removing missing values (response rate was 76.2\%). The participants were $43.3 \%$ female and $76.6 \%$ non-managers. Their average tenure was 7.73 years $(\mathrm{SD}=6.52$ years). The age distributions were $20-29(48.1 \%), 30-39(32.0 \%)$, $40-49(16.2 \%)$, and above 50 years (3.7\%). The organization sizes (number of beds) were 0 (3.8\%), 1-100 (5.2\%), 100-299 (53.3\%), 300-499 (25.8\%), and 500 or more (12.0\%).

Measures. Reflection on success and failures (time 1) were assessed with the same measures used in Study 1.

Work authenticity (time 2) was assessed with a four-item scale of authentic living, developed by Van den Bosch and Taris (2014), on a five-point Likert scale ranging from 1 (strongly disagree) to 5 (strongly agree).

Work engagement (time 2) was assessed with a nine-item scale, developed by Schaufeli et al. (2006), on a five-point Likert scale ranging from 1 (never) to 5 (always).

Strengths use (time 2) was assessed using a four-item scale developed by Van Woerkom et al. (2016b), on a five-point Likert scale ranging from 1 (never) to 5 (always). Since 
the original scales measured the weekly strengths use, the present research replaced "this week" with "this month" in the survey items.

As control variables, gender $(1=$ female and $2=$ male $)$, position $(1=$ non-manager, 2 $=$ junior manager, $3=$ middle manager, $4=$ deputy manager, and $5=$ senior manager), tenure (years of experience in the organization), and size of organization (number of beds: $1=0,2=$ $1-100,3=100-299,3=300-499$, and $5=500$ or more) were included in the model.

\section{Table 2.}

Comparison of CFAs (Study 2)

\begin{tabular}{lcccccc}
\hline \multicolumn{1}{c}{ Models } & $\chi^{2}$ & $d f$ & $\Delta \chi^{2}$ & CFI & SRMR & RMSEA \\
\hline 5-Factor model & 451.08 & 314 & & .933 & .048 & .039 \\
4-Factor model (ROS + ROF) & 598.25 & 318 & $147.17^{* * *}$ & .862 & .069 & .055 \\
3-Factor model (ROS + ROF + WA) & 782.85 & 321 & $184.60^{* * *}$ & .773 & .119 & .070 \\
2-Factor model (ROS + ROF + WA + WE) & 1022.77 & 323 & $239.92^{* * *}$ & .657 & .121 & .086 \\
1-Factor model (ROS + ROF + WA + WE + SU) & 1337.22 & 324 & $314.45 * * *$ & .503 & .133 & .104 \\
\hline
\end{tabular}

Notes. In the 5-factor model, each variable was loaded on a single factor. In the 4-factor model, reflection on success (ROS) and reflection on failures (ROF) were combined. In the 3-factor model, ROS, ROF, and work authenticity (WA) were combined. In the 2factor model, ROS, ROF, WA, and work engagement (WE) were combined. In the 1-factor model, all variables were combined in a single factor. $\mathrm{SU}=$ strengths use. ${ }^{* * *} p<.001$.

Table 3.

Descriptive statistics, AVE, CR and correlation matrix (Study 2)

\begin{tabular}{|c|c|c|c|c|c|c|c|c|c|c|c|c|c|}
\hline Variable & $M$ & $S D$ & $A V E$ & $C R$ & 1 & 2 & 3 & 4 & 5 & 6 & 7 & 8 & 9 \\
\hline 1. Gender & 1.57 & 0.50 & - & - & - & & & & & & & & \\
\hline 2. Position & 1.27 & 0.54 & - & - & .11 & - & & & & & & & \\
\hline 3. Tenure & 7.73 & 6.52 & - & - & .03 & $.58 * * *$ & - & & & & & & \\
\hline 4. Size of organization & 3.37 & 0.90 & - & - & .01 & .09 & .03 & - & & & & & \\
\hline 5. Reflection on success & 3.25 & 0.64 & .57 & .87 & .02 & -.11 & -.07 & .08 & - & .15 & .04 & .10 & .04 \\
\hline 6. Reflection on failures & 3.78 & 0.49 & .47 & .81 & -.02 & .04 & -.03 & $.13 *$ & $.39_{* * *}^{*}$ & - & .01 & .06 & .01 \\
\hline 7. Work authenticity & 3.42 & 0.60 & .49 & .79 & .01 & .03 & .07 & -.01 & $.23_{* * *}^{*}$ & .10 & - & .27 & .18 \\
\hline 8. Work engagement & 2.95 & 0.64 & .54 & .91 & .09 & -.07 & -.07 & -.03 & $.32 * * *$ & $.25 * * *$ & $.52 * * *$ & - & .24 \\
\hline 9. Strengths use & 2.74 & 0.78 & .74 & .92 & .09 & -.03 & .01 & -.05 & $.21_{* * *}^{*}$ & .08 & $.42_{* * * *}$ & $.49_{* * * *}$ & - \\
\hline
\end{tabular}


Table 4. Results of SEM

\begin{tabular}{|c|c|c|c|c|}
\hline \multicolumn{3}{|c|}{ Structural path } & \multirow{2}{*}{$\begin{array}{c}\begin{array}{c}\text { Standardized } \\
\text { estimate }\end{array} \\
.27\end{array}$} & \multirow{2}{*}{$\frac{t \text {-value }}{3.48^{* * *}}$} \\
\hline Reflection on success & $\Rightarrow$ & Work authenticity & & \\
\hline Reflection on failures & $\Rightarrow$ & Work authenticity & .01 & 0.14 \\
\hline Reflection on success & $\Rightarrow$ & Work engagement & .26 & $3.66^{* * *}$ \\
\hline Reflection on failures & $\Rightarrow$ & Work engagement & .18 & $2.43^{*}$ \\
\hline Reflection on success & $\Rightarrow$ & Strengths use & .25 & $3.28^{* *}$ \\
\hline Reflection on failures & $\Rightarrow$ & Strengths use & -.02 & -0.28 \\
\hline \multicolumn{5}{|l|}{ Control variables } \\
\hline Gender & $\Rightarrow$ & Work authenticity & .02 & 0.33 \\
\hline Position & $\Rightarrow$ & Work authenticity & .02 & 0.25 \\
\hline Tenure & $\Rightarrow$ & Work authenticity & .09 & 1.22 \\
\hline Size of organization & $\Rightarrow$ & Work authenticity & -.01 & -0.20 \\
\hline Gender & $\Rightarrow$ & Work engagement & .10 & 1.68 \\
\hline Position & $\Rightarrow$ & Work engagement & -.04 & -0.50 \\
\hline Tenure & $\Rightarrow$ & Work engagement & -.03 & -0.39 \\
\hline Size of organization & $\Rightarrow$ & Work engagement & -.08 & -1.39 \\
\hline Gender & $\Rightarrow$ & Strengths use & .09 & 1.45 \\
\hline Position & $\Rightarrow$ & Strengths use & -.05 & -0.61 \\
\hline Tenure & $\Rightarrow$ & Strengths use & .04 & 0.57 \\
\hline Size of organization & $\Rightarrow$ & Strengths use & -.07 & -1.22 \\
\hline Reflection on failures & $\Leftrightarrow$ & Reflection on success & .48 & $8.57^{* * *}$ \\
\hline Strengths use & $\Leftrightarrow$ & Work engagement & .50 & $10.11^{* * *}$ \\
\hline Work authenticity & $\Leftrightarrow$ & Work engagement & .55 & $10.44^{* * *}$ \\
\hline Work authenticity & $\Leftrightarrow$ & Strengths use & .42 & $7.22^{* * *}$ \\
\hline
\end{tabular}




\section{Results}

The Cronbach's alphas and composite reliabilities were .87 and .87 for reflection on success, .81 and .81 for reflection on failures, .92 and .92 for strengths use, .78 and .79 for work authenticity, and .91 and .91 for work engagement, respectively. These scores were above the recommended .70, indicating sufficient internal consistency.

Figure 1. Summary of SEM results

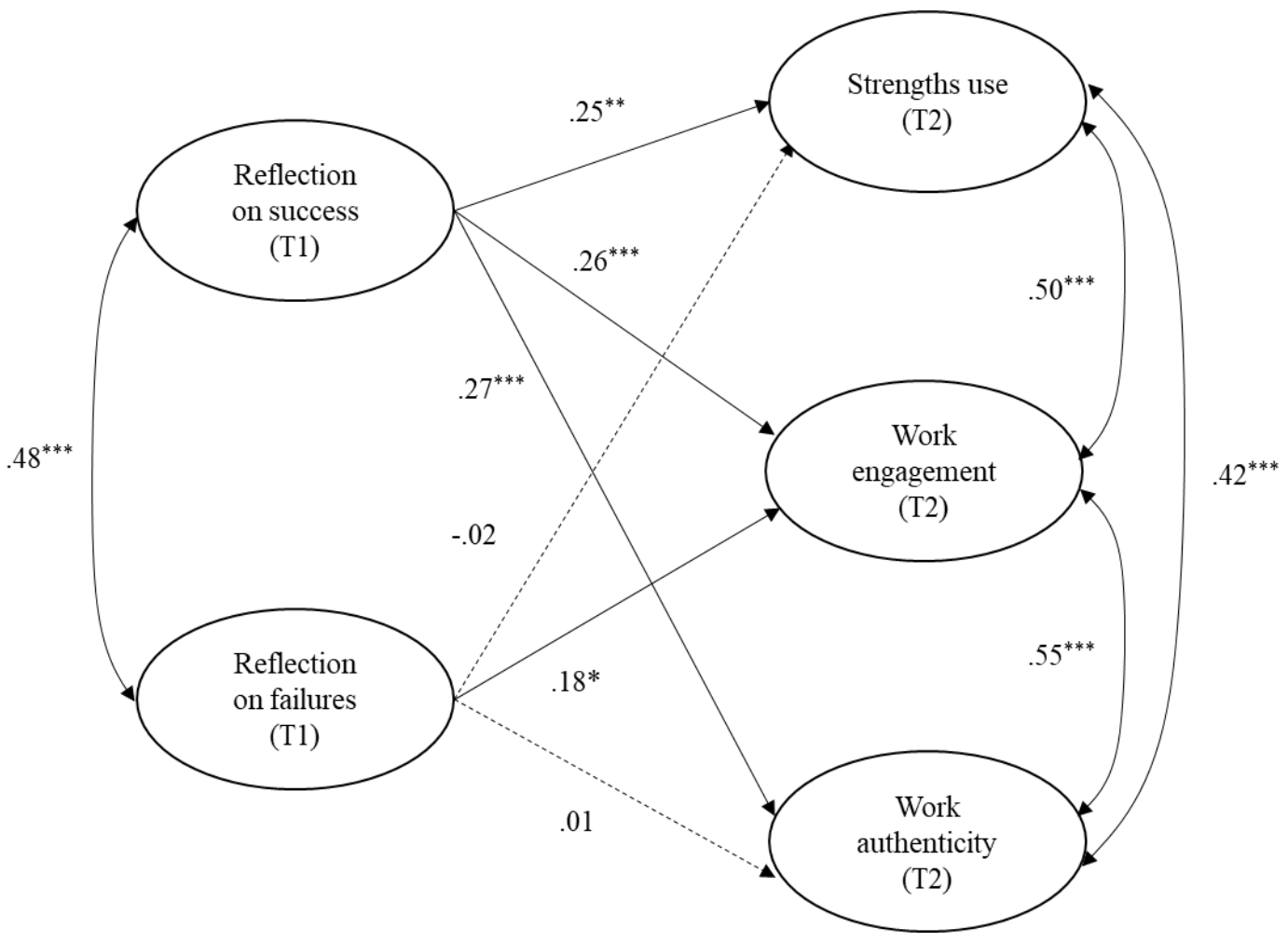

Notes: $* p<.05, * * p<.01, * * * p<.001$.

To examine the discriminant validity, a series of CFAs were conducted. The two-factor solution with reflection on success and failures showed acceptable fit $\left(\chi^{2}=76.76\right.$, $\mathrm{df}=34$, comparative fit index $(\mathrm{CFI})=.942$, standardized root mean square residual $(\mathrm{SRMR})=.045$, root mean square error of approximation $($ RMSEA) $=.066)$, whereas all items loaded significantly on the latent variables ranging from .59 to .83 (Table 1). In addition, Table 2 
indicated that the five-factor model (reflection on success, reflection on failures, work authenticity, work engagement, and strengths use) was significantly better than the four-factor model that combined reflection on success with reflection on failures $\left(\Delta \chi^{2}=147.17, \Delta d f=4, p\right.$ $<.001$ ). As shown in Table 3, the average variance extracted (AVE) for each construct was greater than the shared variance. These results support discriminant validity of reflection on success and failures scales.

The convergent validity was examined using SEM. Table 4 and Figure 1 show that reflection on success was positively related to work authenticity $(\gamma=.27, p<.001)$, work engagement $(\gamma=.26, p<.001)$, and strengths use $(\gamma=.25, p<.01)$. However, reflection on failures was not significantly related to work authenticity $(\gamma=.01, \mathrm{~ns})$ or strengths use $(\gamma=-.02$, $n s)$, and was positively related to work engagement $(\gamma=.18, p<.05)$. These results were in line with the predictions, and showed the convergent validity of the scales.

\section{Discussion}

Reflection is believed to play a key role in promoting learning from experiences (Kolb, 1984; Korthagen, 2005). This study aimed to develop and validate the scales of "reflection on success" and "reflection on failures," drawing on positive psychology (Peterson and Seligman, 2004; Seligman et al., 2005, 2009), broaden-and-build theory (Fredrickson, 2001), and JD-R theory (Bakker and Demerouti, 2014, 2017).

There are some findings and theoretical implications. First, the reliability and validity of the scales of reflection on success and failures were confirmed. Although the strengths- and deficiency-based learning strategies have been investigated in past research (e.g., Hiemstra and Van Yperen, 2015; Van Woerkom et al., 2016a), few studies examined the reflection process using the strengths-based approach. Importantly, reflection on success and failures were conceptually different from positive and negative work reflection (Fritz and Sonnentag, 2006) 
that focus on positive and negative work events, respectively. That is, reflection on success and failures refer to learning-related constructs for increasing one's strengths and improving upon weaknesses. Moreover, reflection has been mainly classified into "(general) reflection - critical reflection" (Gray, 2007; Kember et al., 2000; Reynolds, 1998), whereas this study extended the literature on reflection by introducing the "success - failures" dimension, drawing on positive psychology (Peterson and Seligman, 2004; Seligman et al., 2005, 2009).

Second, the results showed that reflection on success enhanced strengths use, work authenticity, and work engagement, suggesting that reflection on success can be a facilitator of strengths-based learning strategies (Hiemstra and Van Yperen, 2015). The findings can be explained by the argument that reflection on success stimulates employees to identify their strengths and true selves and build personal resources for work engagement, as suggested by broaden-and-build theory (Fredrickson, 2001) and JD-R theory (Bakker and Demerouti, 2014, 2017). Since strengths use has proven to enhance several types of well-being (Allan and Duffy, 2014; Douglass and Duffy, 2015; Govindji and Linley, 2007; Proctor et al., 2011; Wood et al., 2011), reflection on success may play a critical role in the practice of the strengths-based approach. Therefore, this study extended the literature on strengths-based approach by incorporating reflection on success.

Third, reflection on failures had no significant impact on strengths use and work authenticity but enhanced work engagement. These findings indicated that reflection on failures plays a limited role in identifying individuals' characteristics and values, while it has a positive influence on work-related well-being. The positive effect on work engagement may be due to the characteristics of reflection on failures, which aims to improve individuals' capacity, which corresponds to past research on learning from mistakes and errors (Edmondson, 2004; Reason, 1990). Notably, although Van Woerkom et al. (2016a) reported no significant effect of deficit correction behavior on performance, this study found a positive relationship between reflection 
on failures and work engagement. The findings suggest that employees need to reflect both on their success and failures to enhance work-related well-being.

These findings have some practical implications. Since employees tend to focus on their weaknesses and deficiencies (Aguinis et al., 2012), it is important to encourage them to reflect not only on failures but also on success. In particular, when adopting the strengths-based coaching and mentoring, managers should facilitate employees to review their success at work to identify their strengths, as suggested by positive psychology exercise (Seligman et al., 2005) and strengths-based performance appraisal (Bouskila-Yam and Kluger, 2011). Additionally, managers should be aware that reflection on failures is effective for promoting work engagement, but it has no impact on strengths use and work authenticity.

The limitations of the present research must be discussed. First, the research samples included only medical professionals in Japanese healthcare institutions. There is the possibility that professional workers are deeply committed to reflective activities more than nonprofessional workers. Thus, future research needs to validate the scales with samples from a wide range of occupations, countries, and cultural backgrounds. Second, this study developed the measures using self-report survey data. To further validate the scales, it is necessary to measure external dependent variables such as performance data assessed by supervisors, using a longitudinal survey. Third, one item of reflection on success seems to be described with the neutral expression "I often reflect on my work behaviors to see if I could have done something better." However, the item was highly correlated with other items (ranging from .64 to .84 in Study 1 and ranging from .52 to .73 in Study 2). In addition, there was no item in which Cronbach's alpha increases if it is deleted. These results suggest that the item may be appropriate as an item for reflection on success. Fourth, as critical reflection is imperative for transformative learning (Mezirow, 1990), the relationship between critical reflection and reflection on success and failures merits investigation. Finally, the present research examined the consequences of reflection on success and failures; their antecedents should be explored in 
future research.

\section{Funding}

This work was supported by the Japan Society for the Promotion of Science [grant number 18K01744].

\section{References}

Aguinis, H., Gotfredson, R. K., and Joo, H. (2012), "Delivering effective performance feedback: The strengths-based approach", Business Horizons, Vol. 55, pp. 105-111.

Allan, B.A. and Duffy, R.D. (2014), "Examining moderators of signature strengths use and well-being: Calling and signature strengths level”, Journal of Happiness Studies, Vol. 15, pp. 323-337.

Andrews, M. C. and Kacmar, K. M. (2001), "Impression management by association: Construction and validation of a scale", Journal of Vocational Behavior, Vol. 58, pp. 142 161.

Bakker, A. B. and Demerouti, E. (2014), "Job demands - resources theory", in Chen, P Y. and Cooper, C. L. (Eds), Work and wellbeing: A Complete Reference Guide, Volume III, Wiley, pp. 37-64.

Bakker, A. B. and Demerouti, E. (2017), "Job demands-resources theory: Taking stock and looking forward”, Journal of Occupational Health Psychology, Vol. 22 No. 3, pp. 273-285.

Bouskila-Yam, O. and Kluger, A.N. (2011), "Strength-based performance appraisal and goal setting", Human Resource Management Review, Vol. 21, pp. 137-147.

Bowers, K. (2009), "Making the most of human strengths" in Lopez, S. J. (Ed), Positive Psychology: Exploring the Best in People, Praeger, CT, pp. 23-36.

Cascio, W.F. (2012), "Methodological issues in international HR management researc", International Journal of Human Resource Management, Vol. 23 No. 12, pp. 2532-2545.

Choi, J. N. and Moran, S. V. (2009), "Why not procrastinate?: Development and validation of a new active procrastination scale”, Journal of Social Psychology, Vol. 149 No.2, pp. 195 
211.

Chuang, A.,Shen, C., and Judge, T. A. (2016), "Development of a multidimensional instrument of person-environment fit: The perceived person-environment fit scale (PPEFS)", Applied Psychology: An International Review, Vol. 65 No. 1, pp. 66-98.

Churchill, G. A. (1979), "A paradigm for developing better measures of marketing constructs", Journal of Marketing Research, Vol. 16 No. 1, pp. 64-73.

Douglass, R.P. and Duffy, R.D. (2015), "Strengths use and life satisfaction: A moderated mediation approach”, Journal of Happiness Studies, Vol. 16, pp. 619-632.

Edmondson, A. C. (2004), "Learning from mistakes is easier said than done: Group and organizational influences on the detection and correction of human error", Journal of Applied Behavioral Science, Vol. 40 No. 1, pp. 66-90.

Fredrickson, B. L. (2001), “The role of positive emotions in positive psychology: The broadenand-build theory of positive emotions", American Psychologist, Vol. 56 No. 3, pp. 218 226.

Fritz, C. and Sonnentag, S. (2006), "Recovery, well-being, and performance-related outcomes: The role of workload and vacation Experiences", Journal of Applied Psychology, Vol. 91 No. 4, pp. 936-945.

Govindji, R. and Linley, A. (2007), "Strengths use, self-concordance and well-being: Implications for Strengths Coaching and Coaching Psychologists", International Coaching Psychology Review, Vol. 2 No. 2, 143-153.

Gray, D.E. (2007), "Facilitating management learning developing critical reflection through reflective tools", Management Learning, Vol. 38 No. 5, pp. 495-517.

Gilliam, D. A., \& Voss, K. (2013), “A proposed procedure for construct definition in marketing”, European Journal of Marketing, Vol. 47 No. 1/2, pp. 5-26.

Guo, Y., Lam, L., Plummer, V., Cross, W. and Zhang, J. (2019), “A WeChat-based “Three Good Things" positive psychotherapy for the improvement of job performance and self- 
efficacy in nurses with burnout symptoms: A randomized controlled trial", Journal of Nursing Management, Vol. 28, pp. 480-487.

Harter, S. (2002), “Authenticity”, in Snyder, C.R. and Lopez, S.J. (Eds), Handbook of Positive Psychology, Oxford University Press, Oxford, pp. 382-394.

Hatton, N. and Smith,f D. (1995), "Reflection in teacher education: Towards definition and implementation", Teaching \& Teacher Education, Vol. 11 No. 1, pp. 33-49.

Hayes, B., Bonner, A. and Pryor, J. (2010), "Factors contributing to nurse job satisfaction in the acute hospital setting: a review of recent literature", Journal of Nursing Management, Vol. 18, pp. 804-814.

Hiemstra, D. and Van Yperen, N. W. (2015), "The effects of strength-based versus deficit-based self-regulated learning strategies on students' effort intentions", Motivation and Emotion, Vol. 39 No. 5, pp. 656-668.

Hinkin, T. R. (1998), “A brief tutorial on the development of measures for use in survey questionnaires”, Organizational Research Methods, Vol. 1 No. 1, pp. 104-121.

Holt, D. T., Armenakis, A. A., Feild, H. S., and Harris, S. G. (2007), "Readiness for organizational change: The systematic development of a scale", Journal of Applied Behavioral Science, Vol. 43 No. 2, pp. 232-255.

Hung, K. and Petrick, J. F. (2011), "Why do you cruise? Exploring the motivations for taking cruise holidays, and the construction of a cruising motivation scale", Tourism Management, Vol. 32, pp. 386-393.

Judge, W. and Douglas, T. (2009), "Organizational change capacity: The systematic development of a scale", Journal of Organizational Change Management, Vol. 22 No. 6, pp. 635-649.

Kember, D., Leung, D.Y.P, Jones, A., Loke, A.Y., Mckay, J., Singlair, K., Tse, H., Webb, C., Wong, F.K.Y. Wong, M. and Yeung, E. (2000), "Development of a questionnaire to 
measure the level of reflective thinking", Assessment \& Evaluation in Higher Education, Vol. 25 No. 4, pp. 381-395.

Kluger, A.N. and Nir, D. (2010), “The feedforward interview”, Human Resource Management Review, Vol. 20, pp. 235-246.

Kolb, D.A. (1984), Experiential Learning: Experience as the Source of Learning and Development. Prentice Hall, Englewood Cliffs, NJ.

Korthagen, F. A. J. (2005), "The organization in balance reflection and intuition as complementary processes", Management Learning, Vol. 36 No. 3, pp. 371-387.

Metin, U.B., Taris, T.W., Peeters, M.C.W., Van Beek, I. and Van den Bosch, R. (2016), "Authenticity at work: A job-demands resources perspective", Journal of Managerial Psychology, Vol. 31 No. 2, pp. 483-499.

Mezirow, J. (1990), "How critical reflection triggers transformative learning”, in Mezirow, J. (Ed), Fostering Critical Reflection in Adulthood: A Guide to Transformative and Emancipatory Learning. Jossey-Bass, San Francisco, pp. 1-20.

Mongrain, M. and Anselmo-Matthews, T. (2012), “Do positive psychology exercises work? A replication of Seligman et al. (2005)", Journal of Clinical Psychology, Vol. 68 No. 4, pp. 382-389.

Nilsen, P., Nordström, G. and Ellström, P. (2012), "Integrating research-based and practicebased knowledge through workplace reflection", Journal of Workplace Learning, Vol. 24 No. 6, pp. 403-415.

Peterson, C. and Seligman, M.E.P. (2004), Character Strengths and Virtues: A Handbook and Classification. American Psychological Association, Washington, DC.

Proctor, C. Maltby, J. and Linley, P.A. (2011), "Strengths use as a predictor of well-being and health-related quality of life", Journal of Happiness Studies, Vol. 12, pp. 153-169.

Reason, J. (1990), Human Error. Cambridge University Press, New York, NY. 
Reynolds, M. (1998), "Reflection and critical reflection in management learning", Management Learning, Vol. 29 No. 2, pp. 183-200.

Schaufeli, W.B., Bakker, A.B. and Salanova, M. (2006), "The measurement of work engagement with a short questionnaire", Educational and Psychological Measurement, Vol. 66 No. 4, pp. 701-716.

Schippers, M.C., Homan, A.C. and Van Knippenberg, D. (2013), "To reflect or not to reflect: Prior team performance as a boundary condition of the effects of reflexivity on learning and final team performance”, Journal of Organizational Behavior, Vol. 34 No. 6-23.

Schön, D.A. (1983), The Reflective Practitioner: How Professionals Think in Action. Basic Books, New York, NY.

Seligman, M.E.P., Ernst, R.M., Gillham, J., Reivich, K. and Linkins, M. (2009), "Positive education: positive psychology and classroom interventions", Oxford Review of Education, Vol. 35 No. 3, pp. 293-311.

Seligman, M.E.P., Steen, T.A., Park, N. and Peterson, C. (2005), "Positive psychology progress: Empirical validation of interventions", American Psychologist, Vol. 60 No. 5, pp. 410421.

Van den Bosch, R. and Taris, T. W. (2014), “Authenticity at work: Development and validation of an individual authenticity measure at work", Journal of Happiness Studies, Vol. 15, pp. 1-18.

Van Woerkom, M., Mostert, K., Els, C., Bakker, A. B., de Beer, L. and Rothmann, S. (2016a), "Strengths use and deficit correction in organizations: development and validation of a questionnaire”, European Journal of Work and Organizational Psychology, Vol. 25 No. 6, pp. 960-975.

Van Woerkom, M., Oerlemans, W. and Bakker, A.B. (2016b), "Strengths use and work 
engagement: a weekly diary study", European Journal of Work and Organizational Psychology, Vol. 25 No. 3, pp. 384-397.

Vendrely, A. (2005), "Critical thinking skills during a physical therapist professional education program", Journal of Physical Therapy Education, Vol. 19 No. 1, pp. 55-59.

West, M. A. (2000), "Reflexivity, revolution and innovation in work teams”, in Beyerlein, M. M., Johnson, D.A. and S.T. Beyerlein (Eds.), Product development teams, Vol. 5, JAI Press, Stamford, CT, pp. 1-29.

Wilson, K. S. and Baumann, H. M. (2015), “Capturing a more complete view of employees' lives outside of work: The introduction and development of new interrole conflict constructs”, Personnel Psychology, Vol. 68, pp. 235-282.

Wood, A.M., Linley, P.A., Maltby, J., Kashdan, T. B. and Hurling, R. (2011), “Using personal and psychological strengths leads to increases in well-being over time: A longitudinal study and the development of the strengths use questionnaire", Personality and Individual Differences, Vol. 50, pp. 15-19. 